\title{
Functional defects in phagocytic cells from patients with iron overload
}

\author{
B. Sweder van Asbeck, ${ }^{\star} \ddagger$ Jo J. M. Marx, $\star^{\star} \nmid$ Albert Struyvenberg ${ }^{\star}$ \\ and Jan Verhoef $\ddagger$ \\ Departments of Medicine ${ }^{\star}$, Haematology $\dagger$, and Microbiology $\ddagger$, University \\ Hospital, Utrecht, The Netherlands
}

Accepted for publication 17 November 1983

\begin{abstract}
Summary
Phagocytic functions were studied in patients with iron overload. Phagocytosis of radiolabelled opsonised Staphylococcus aureus by mononuclear (MN) leucocytes and polymorphonuclear (PMN) leucocytes was measured in 15 and I 6 patients, respectively. The intracellular killing capacity of $M N$ and PMN leucocytes of seven and nine patients, respectively, and chemotaxis of PMN leucocytes of eight patients, were assessed also. These cellular functions were compared with phagocytic functions of controls tested on the same day, and with the normal ranges of phagocytic cell functions obtained with $M N$ and PMN leucocytes from 48 and 59 healthy donors, respectively. One or more phagocytic functions were impaired in 62.5 per cent of the patients. Comparison of the various phagocytic functions in patients and simultaneously tested controls showed a significant decrease of the mean phagocytic capacity of the patients' $M N$ and $P M N$ leucocytes $(P<0.015$ and $P<0.03$, respectively), as well as the mean bactericidal activity of the $\mathrm{MN}$ leucocytes $(P<0.05)$ and the mean chemotactic responsiveness of the PMN leucocytes $(P<0.025)$. Patients with excess iron must be regarded as compromised hosts, not only because of the increased availability of iron for bacterial growth, but also because of the associated functional impairment of monocytes and granulocytes.
\end{abstract}

\section{Introduction}

Phagocytic cells play a crucial role in the host defence against invading micro-organisms. Since it became known that the underlying defect in patients with chronic granulomatous disease is a diminished bactericidal activity of the phagocytic cells, ${ }^{1}$ an increasing number of functional disorders of $M N$ and PMN leucocytes in patients with various diseases has been described. ${ }^{2-9}$ All such patients are more susceptible to infection.

Recently we described a diminished phagocytic activity of the $M N$ leucocytes in a patient with haemochromatosis who suffered from Listeria monocytogenes meningitis. ${ }^{10}$ After phlebotomies, this defective phagocytosis became completely normal. It was suggested that not only the increased availability of iron for bacterial growth, but also a deleterious effect of iron on the phagocytic cells favoured susceptibility of the iron-overloaded host to infection with $L$. monocytogenes. Other studies of the role of iron in host defence have also suggested that iron predisposes to infection. ${ }^{11}$ Iron stimulates bacterial

Correspondence should be addressed to: B. S. van Asbeck, MD, Department of Clinical Microbiology, University Hospital, Catharijnesingel IOI, 35 I I GV Utrecht, The Netherlands. 
Phagocyte function in iron overload

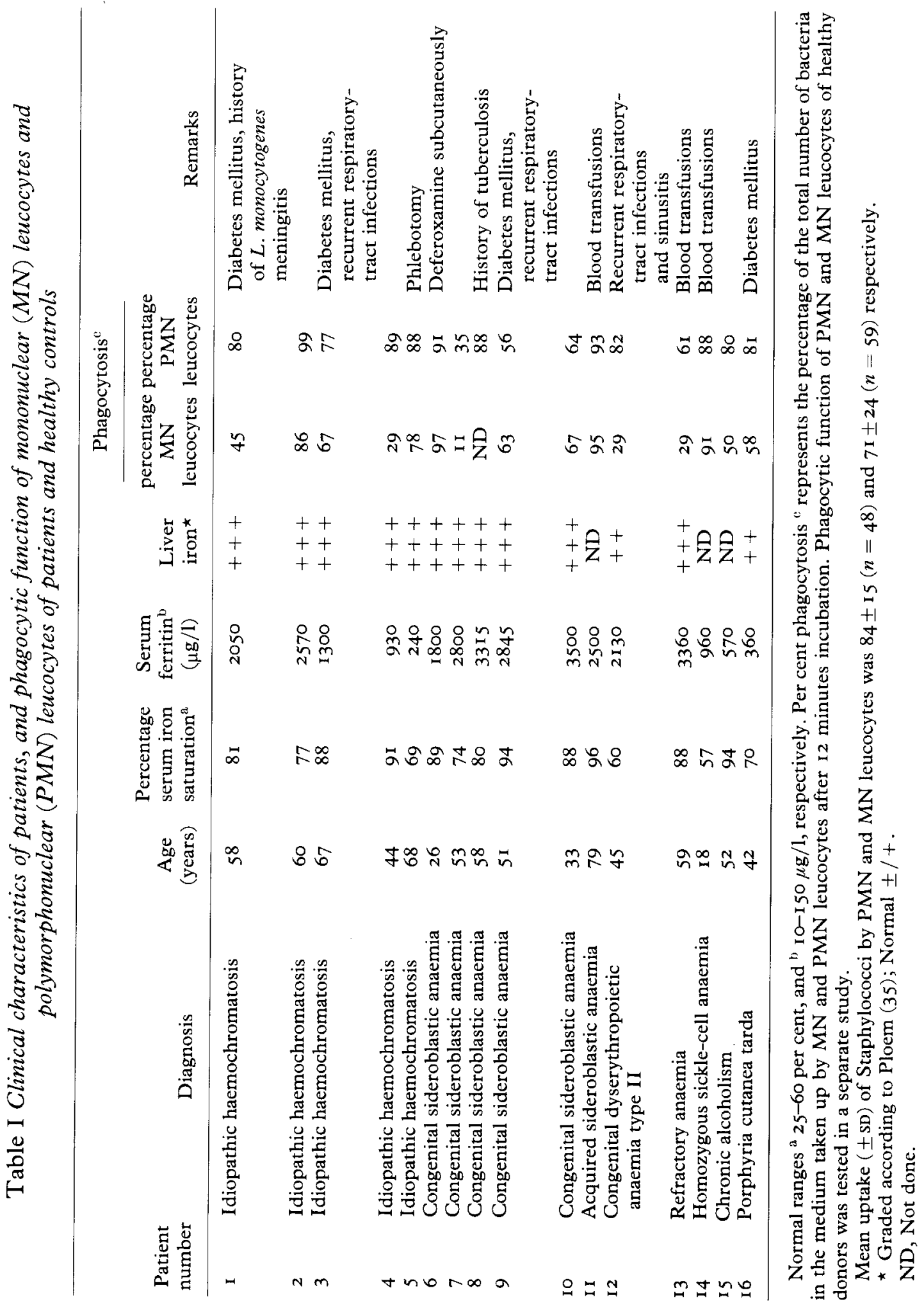


growth, ${ }^{12}$ and in vitro studies have shown that iron impairs leucocyte antibacterial activity. ${ }^{10,13-15}$ These findings led us to investigate $M N$ and PMN leucocyte function in patients with iron overload. Phagocytosis, intracellular killing, and chemotaxis of the phagocytes were assessed. Several significant defects in various $M N$ and PMN leucocyte functions were observed.

\section{Patients and methods}

\section{Patients}

Sixteen patients aged I 8-79 years, with iron overload and I 6 healthy controls, aged i 8-69 years, all without any clinical evidence of infection, were included in the study. The iron status of the patients was assessed by measuring the concentrations of iron, transferrin and ferritin in the serum and in the urine (after intramuscular injection of deferoxamine) as well as in bone marrow and liver biopsy specimens. The controls were healthy members of the laboratory staff who were regularly subjected to routine blood tests.

Relevant clinical characteristics of the patients are summarised in Table I. Five patients had idiopathic haemochromatosis and I I had secondary iron overload. The patients' serum ferritin concentration, which offers a useful clinical index of the size of body iron stores in iron overload, ${ }^{16}$ ranged from 240 to $3500 \mu \mathrm{g} / 1$ (normal range IO-I $50 \mu \mathrm{g} / \mathrm{l}$ ). During assessment of the leucocyte functions, one patient was being treated with subcutaneous deferoxamine, and one with weekly phlebotomies. Three of the patients regularly received blood transfusions, four had diabetes mellitus with well-controlled blood sugar, and three suffered from recurrent respiratory-tract infections. One patient had a history of L. monocytogenes meningitis and another of tuberculosis.

Phagocytic functions of patients and controls were assessed simultaneously in order to exclude experimental errors. All results were compared with the normal ranges (mean \pm 2 SD) for phagocytosis, killing capacity, and chemotaxis of $M N$ and PMN leucocytes as obtained in a separate study with 48 and 59 healthy donors, respectively, aged $16-74$ years.

\section{Leucocytes}

Leucocytes were harvested from $30 \mathrm{ml}$ heparinised venous blood samples according to a modification of Böyum's method. ${ }^{17}$ Briefly, erythrocytes were allowed to settle for one hour in 6 per cent Dextran ' 7 ' (Fluka AG, Buchs, Switzerland). The leucocyte-rich plasma was centrifuged at $\mathbf{r} 60 \mathrm{~g}$ for 5 minutes, and the pellet was resuspended in Eagle's minimum essential medium (MEM) and layered on a Ficoll-Isopaque gradient (Ficoll, Nyegaard, Pharmacia, Uppsala, Sweden; Isopaque, Oslo, Norway). Ater centrifugation at $200 \mathbf{g}$ for 35 minutes, the $M N$ and PMN leucocytes were removed separately and washed twice in MEM. Total and differential leucocyte counts were performed. The leucocyte pellets finally obtained were resuspended to a concentration of $5 \times 10^{6}$ $\mathrm{MN} / \mathrm{ml}$ and $5 \times 10^{6} \mathrm{PMN} / \mathrm{ml}$ in Hanks' balanced salt solution containing $0^{\cdot} \mathrm{I}$ per cent gelatin (GHBSS). Viability was evaluated by trypan blue exclusion and exceeded 95 per cent. 


\section{Culturing and radiolabelling of bacteria}

Staphylococcus aureus Ev., a clinical isolate, was grown for 18 hours in Mueller-Hinton broth (Difco, Detroit, MI, U.S.A.) containing $0.02 \mathrm{mCi}$ $\left[{ }^{3} \mathrm{H}\right]$ methyl-thymidine (specific activity $5 \mathrm{Ci} / \mathrm{mmol}$; Amersham, Bucks, U.K.), washed three times in phosphate-buffered saline (PBS), $\mathrm{pH} 7 \cdot 4$, and suspended to a concentration of $2.5 \times 10^{8}$ colony-forming units $(\mathrm{cfu}) / \mathrm{ml}$ PBS. These bacteria were incubated $\left(37^{\circ} \mathrm{C}\right)$ in pooled normal human serum ( 5 per cent in GHBSS) from Io healthy donors. After 30 minutes the serum was removed by centrifugation, and the opsonised bacteria were resuspended in GHBSS to a concentration of $5 \times 10^{7} \mathrm{cfu} / \mathrm{ml}$.

\section{Phagocytosis and killing assay}

Phagocytosis and killing were quantitatively measured in duplicate as described elsewhere. ${ }^{18}$ Briefly, $0 \cdot 2 \mathrm{ml}$ of the suspension of opsonised bacteria was added to $0.2 \mathrm{ml}$ of the $\mathrm{MN}$ or PMN leucocyte suspension in four polypropylene vials (Biovials, Beckman, Chicago, Il.,U.S.A.). The final bacteria-to-phagocyte ratio was IO: $\mathrm{I}$. The mixtures were incubated in a shaking waterbath at $37^{\circ} \mathrm{C}$. After 2, 6 and 12 minutes, phagocytosis was stopped in one of the vials by adding $3 \mathrm{ml}$ ice-cold PBS. Leucocyte-associated bacteria, i.e. bacteria ingested by and attached to the MN or PMN leucocytes, were then separated from nonleucocyte-associated bacteria by three cycles of centrifugation $\left(\mathrm{I} 60 \mathrm{~g}\right.$ at $4{ }^{\circ} \mathrm{C}$ ). The leucocyte pellets finally obtained were dispersed in $2.5 \mathrm{ml}$ scintillation liquid (toluene containing fluoralloy TLA, Beckman, and $20 \%$ Biosolve, Beckman). Leucocyte-associated radioactivity was measured in a liquid scintillation counter (Mark II, Nuclear Chicago, Chicago, Il., U.S.A.) and expressed as a percentage of the total added radioactivity, i.e. per cent uptake of added $S$. aureus. Total added radioactivity (representing both nonleucocyte-associated and leucocyte-associated bacteria) was determined in the pellet of the fourth vial, obtained by centrifugation at $\mathrm{I} 600 \mathrm{~g}$ for $\mathrm{I} 5$ minutes.

The percentage of viable leucocyte-associated bacteria at 12 minutes was determined in a sample taken from the washed cell suspension, by means of a standard pour-plate technique. The results are expressed as per cent intracellular killing of $S$. aureus by $M N$ and PMN leucocytes after I2 minutes of incubation.

\section{Chemotaxis}

Chemotaxis of PMN leucocytes was determined under agarose according to the method of Nelson and colleagues. ${ }^{19}$ Seven $\mu 1$ of a suspension containing $5 \times 10^{7} \mathrm{PMN}$ leucocytes $/ \mathrm{ml}$ was brought into the centre well. The outer well contained zymosan-activated serum (ZAS) as attractant, and the inner well was filled with GHBSS. The plates were incubated for 18 hours at $37^{\circ} \mathrm{C}$ in a humidified atmosphere containing 5 per cent carbon dioxide in air. Migration distances were measured microscopically and the results expressed as $\mathrm{mm}$ migrated towards ZAS minus the mm of spontaneous migration towards GHBSS. The results represent the mean values of directed migration of samples incubated in triplicate on two plates. 


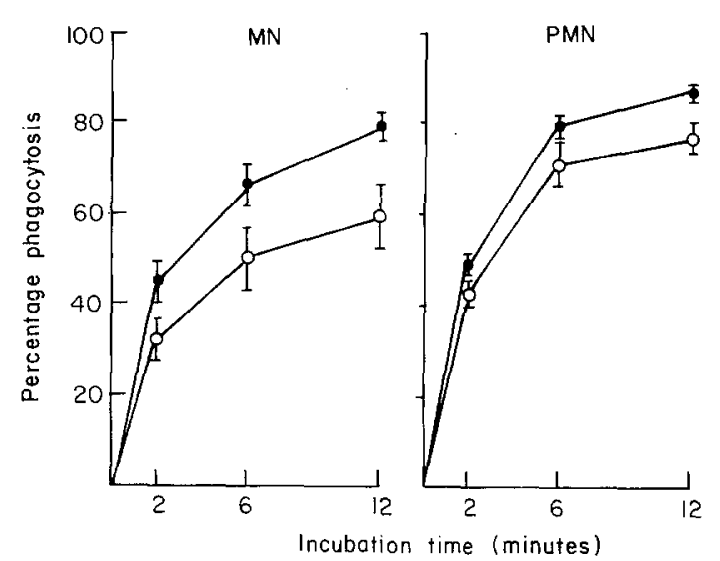

Fig. I. Mean phagocytosis values for mononuclear (MN) leucocytes and polymorphonuclear (PMN) leucocytes derived from 15 and 16 patients with iron overload (O), respectively, and from controls ( ). Data represent the mean uptake of $S$. aureus by $M N$ and PMN leucocytes after 2, 6 and 12 minutes of incubation. Percentage phagocytosis represents the percentage of the total number of bacteria taken up from the medium by $M N$ and PMN leucocytes. Bars indicate SEM.

\section{Statistical analysis}

Two-way analysis of variance ${ }^{20}$ was used to compare the phagocytic capacity of $M N$ and PMN leucocytes from patients with iron overload and controls after the various times of incubation. To compare the intracellular killing scores and migration distances of $\mathrm{MN}$ and PMN leucocytes of the two populations, we used the one-sided Wilcoxon rank-sum test. ${ }^{21}$

\section{Results}

\section{Phagocytosis}

Uptake of $S$. aureus by $\mathrm{MN}$ and PMN leucocytes of 15 and $\mathrm{I} 6$ controls, respectively, and of patients with iron overload, is shown in Fig. I. The mean phagocytic capacity of the patients' MN and PMN leucocytes assessed after 2, 6 and 12 minutes of incubation was significantly lower than that of the control MN and PMN leucocytes $(P<0.015$ and $P<0.03)$, respectively. As can be seen in Table I, 5 of 15 patients had MN leucocytes and 4 of $I 6$ patients had PMN leucocytes with a phagocytic capacity below the normal range obtained with $M N$ and PMN leucocytes from 48 and 59 donors, respectively (only the values for phagocytosis after I2 minutes of incubation are shown). In two patients with defective $\mathrm{MN}$ phagocytosis, bacterial uptake by PMN leucocytes was also impaired.

\section{Bactericidal activity}

The mean killing capacity of MN leucocytes, which was studied in seven patients, was significantly lower than intracellular killing by control $\mathrm{MN}$ leucocytes $(P<0.05)$ (Fig. 2). Also in Fig. 2 is shown the normal range of bactericidal activity of $M N$ and PMN leucocytes of 52 donors. As may be seen, the killing capacity of $\mathrm{MN}$ leucocytes of three patients was below the normal 


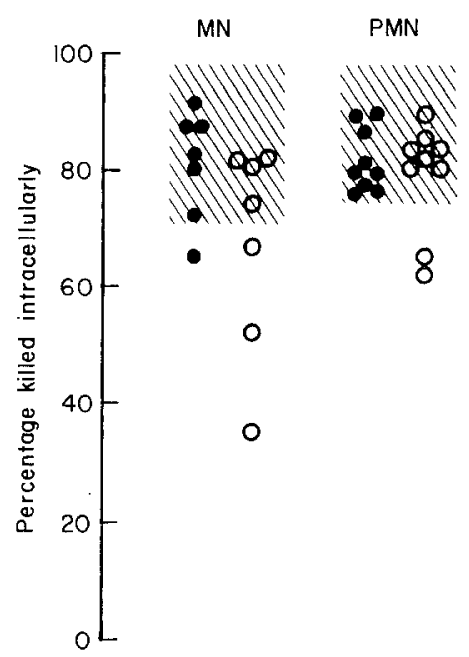

Fig. 2. Intracellular killing of $S$. aureus by mononuclear (MN) leucocytes and polymorphonuclear (PMN) leucocytes from 7 and 9 patients with iron overload $(O)$, respectively, and from controls (O). Percentage killed bacteria represents the percentage of leucocyte-associated bacteria killed after 12 minutes of incubation. The shaded areas indicate the normal range (mean $\pm S D$ ) of the killing capacity of MN and PMN leucocytes of 52 donors.

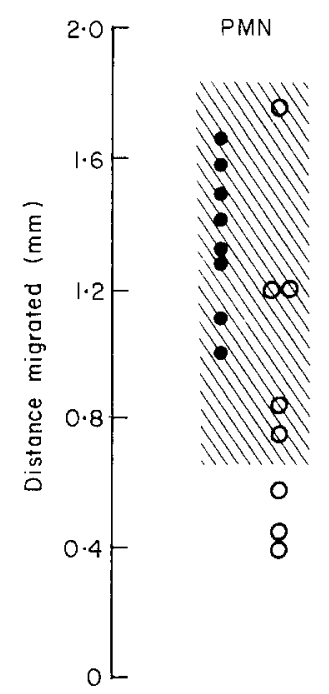

Fig. 3. Chemotaxis of polymorphonuclear (PMN) leucocytes from 8 patients with iron overload $(\mathrm{O})$, and from controls (O). Migration distances represent the distance migrated in 18 hours by phagocytes under agarose. The shaded area represents the normal range (mean $\pm \mathrm{SD}$ ) of chemotaxis by PMN leucocytes of 23 donors.

range, whereas only one control had $M N$ leucotyes with a killing capacity below normal. In two out of nine patients, the PMN leucocytes had a killing capacity below the normal range, and the $\mathrm{MN}$ leucocytes of both of these patients showed similar impairment. In only one patient were the phagocytosis and killing capacity of both $\mathrm{MN}$ and PMN leucocytes below the normal range. 


\section{Chemotaxis}

Compared with control PMN leucocytes, migration of PMN leucocytes from eight iron-overloaded patients was significantly decreased $(P<0.025)$ (Fig. 3). In three patients, PMN leucocyte chemotaxis was below the normal range obtained from 23 donors. Both chemotaxis and phagocytosis were impaired in two patients.

\section{Discussion}

The results show that in Io of the 16 patients $(62.5$ per cent $)$ with iron overload in whom phagocytosis, intracellular killing, and/or chemotaxis of $M N$ or PMN leucocytes were assayed, one or more of these functions were below the normal range. When the phagocytic functions of patients were compared with those of simultaneously tested controls, a significant reduction was found in the phagocytic capacity, the $M N$ leucocyte bactericidal activity, and in the leucocyte chemotactic responsiveness of the patient's $M N$ and PMN leucocytes.

Although our patients had various underlying diseases, they all suffered from iron overload; this was established in several ways (see Table I). Certain diseases such as diabetes ${ }^{5,22-24}$ and acute infections ${ }^{6}$ are sometimes associated with functional defects in phagocytic cells. Functional abnormalities in diabetic PMN leucocytes disappear when the blood sugar concentration is controlled. ${ }^{22-24}$ During assessment of the various phagocytic functions, patients as well as controls were free of infection, and the blood sugar of the four patients who suffered from diabetes mellitus was well controlled. It is therefore unlikely that the reduced phagocytic functions observed in the present study were related to one of these conditions. The assumption that the iron overload was responsible for our observations is supported by our recent report concerning a patient with haemochromatosis and impaired phagocytic function of the $M N$ leucocytes, the function of which became normal after several phlebotomies. ${ }^{10}$

It was not possible to establish significant correlation between one of the measurements used to assess iron overload and any of the phagocytic cell functions tested. This makes the results not easy to explain. It is possible that our assay systems were not optimum for detecting every defect in the function of the phagocytic cells. In our standard assay we used a PMN leucocyte: bacteria ratio of $\mathrm{I}:$ IO. It is possible that with different ratios defects in more patients might have been seen. Our assay, however, has been used to detect defects in many different patients. We were able to show a diminished phagocytosis with this assay in patients with recurrent staphylococcal infections. ${ }^{6}$ It is also possible that our group of patients was too heterogeneous. On the other hand toxicity of iron is non-specific, and many features such as the concentration of iron in a particular system or the sensitivity of the target to iron-induced alterations may play a role. Furthermore, since the noxious effect of iron seems to be the result of oxidation reactions, ${ }^{25}$ factors involved in antioxidant protection such as the concentrations of ascorbic acid and vitamin $E$ in the patients might also have influenced the results of the assays.

Iron plays a crucial role in the host defence against micro-organisms. ${ }^{11,12}$ It is used by bacteria, and a decrease in available iron-due, for example, to 
binding by lactoferrin - results in bacteriostasis. ${ }^{26}$ Iron, however, may also affect the phagocytic system. There are several reports concerning the influence of iron on phagocytic cells in vitro. ${ }^{10,11,13-15}$ Excess iron decreases chemotactic responsiveness ${ }^{15}$ and enhances the ability of ingested micro-organisms to proliferate within PMN leucocytes by lowering bactericidal capacity..$^{13} \mathrm{We}$ found a dose-dependent inhibitory effect of iron on the phagocytic capacity of $M N$ and PMN leucocytes ${ }^{19}$ and, in the same study, ferritin isolated from the plasma of a patient with idiopathic haemochromatosis did not suppress phagocytic cell function. Our results, and the findings of other investigators, suggest that functional defects of phagocytes in patients with iron overload may be due to iron. Nevertheless, how iron affects the phagocytes is not clearly understood. Impairment of the microbicidal activity of PMN leucocytes in the presence of ferrous ions has been attributed to inactivation of cationic proteins ${ }^{13}$ such as myeloperoxidase, ${ }^{27}$ and to the reduction of hydrogen peroxide to water, ${ }^{14}$ so that this compound is not available for bacterial killing. Reduction of hydrogen peroxide induced by ferrous ions, however, leads in the first instance to the formation of a hydroxyl radical ${ }^{28,29}$ which can destroy almost all known biomolecules. ${ }^{30,31}$ Although a hydroxyl radical can contribute to the bacterial activity of phagocytes ${ }^{32}$ it has also been held responsible for damage to the white blood cell itself. ${ }^{33}$ Thus, it is possible that the impaired phagocyte in patients with iron overload is due to enhanced production of toxic oxygen species. This hypothesis is supported by the recent report of increased generation of hydroxyl radicals by human neutrophil leucocytes during exposure to iron. ${ }^{34}$

In summary, excess of iron may enhance bacterial virulence ${ }^{11,12}$ and may impair the host's phagocytic cellular defences against micro-organisms. It is important that the phagocytic cells of patients with iron overload are tested. Further study may lead to the conclusion that patients with iron overload should be regarded as immunocompromised hosts especially vulnerable to infection.

\section{References}

r. Quie PG, White JG, Holmes G, Good RA. In vitro bactericidal capacity of human polymorphonuclear leukocytes: diminished activity in chronic granulomatous disease of childhood. f Clin Invest 1967 ; 46: 668-679.

2. Goldman JM, Th'ng KH. Phagocytic function of leukocytes from patients with acute myeloid and chronic granulocytic leucaemia. Br $\mathcal{F}$ Haematol 1973; 25: 299-308.

3. Steigbigel RT, Lambert LH, Remmington JS. Polymorphonuclear leukocyte, monocyte and macrophage bactericidal function in patients with Hodgkin's disease. $\mathcal{F}$ Lab Clin Med 1976 ; 88: $54-62$.

4. Salant DJ, Glover AM, Anderson R, Meyers AM, Rabkin R, Myburth JA, Rabson AR. Depressed neutrophil chemotaxis in patients with chronic renal failure and after renal transplantation. F Lab Clin Med 1976; 88: 536-545.

5. Bagdade JD. Phagocytic and microbicidal function in diabetes mellitus. Arch Endocrinol Suppl 205, 1976; 83: 27-33.

6. Verbrugh HA, van Dijk WC, Hendrickx GFM, et al. Phagocytic and chemotactic function of polymorphonuclear and mononuclear leukocytes in patients with recurrent staphylococcal infections. Scand $\mathcal{F}$ Infect Dis 1980; 12: I I I-I 16.

7. Hassner A, Kletter Y, Shlag D, Yedvab M, Aronson M, Shibolet S. Impaired monocyte function in liver cirrhosis. $B r$ Med $\mathcal{f}$ I 981 ; 282: $1262-1263$.

8. Heck EL, Browne L, Curreri PW, Baxter CR. Evaluation of leukocyte function in burned individuals by in vitro oxygen consumption. F Trauma $1975 ; 15$ : 486-489. 
9. Hurst NP, Nuki G. Evidence for defect of complement-mediated phagocytosis by monocytes from patients with rheumatoid arthritis and cutaneous vasculitis. $\mathrm{Br} M e d \mathcal{F}_{1981}$; 282: $208 \mathrm{I}-2083$.

Io. Van Asbeck BS, Verbrugh HA, van Oost BA, Marx JJM, Imhof HW, Verhoef J. Listeria monocytogenes meningitis and decreased phagocytosis associated with iron overload. $\mathrm{Br}$ Med f I $982 ; 284: 542-544$.

I1. Weinberg ED. Iron and infection. Microbiol Rev $1978 ; 42: 45-66$.

12. Payne SM, Finkelstein RA. The critical role of iron in host-bacterial interactions. $f$ Clin Invest $1978 ; 61$ : I428-I 440 .

13. Gladstone GP, Walton E. The effect of iron and haematin on the killing of staphylococci by rabbit polymorphs. Br F Ex Pathol I971; 52: 452-464.

I4. Kaplan SS, Quie PG, Basford RE. Effect of iron on leukocyte function: inactivation of $\mathrm{H}_{2} \mathrm{O}_{2}$ by iron. Infect Immunol $1975 ;$ r : 303-308.

15. Ward PA, Goldschmidt P, Green ND. Suppressive effect of metal salts on leucocyte and fibroblastic function. $\mathcal{F}$ Reticuloendothel Soc 1975; 18: 31 3-32 I.

I6. Beamish MR, Walker R, Miller F, Worwood M, Jacobs A, Williams R, Corrigal A. Transferrin iron, chelatable iron and ferritin in idiopathic haemochromatosis. Br $\mathcal{F ~ H a e m a t o l}$ 1974; $27: 219-228$.

17. Böyum A. Isolation of mononuclear cells and granulocytes from human blood. Scand $\mathcal{F}$ Clin Invest Suppl 1968; $97:$ 77-89.

I8. Verbrugh HA, Peters R, Peterson PK, Verhoef J. Phagocytosis and killing of staphylococci by human polymorphonuclear and mononuclear leukocytes. $7 \mathrm{Clin}$ Pathol $1978 ; 31$ : 539-545.

19. Nelson RD, Quie PG, Simmons RL. Chemotaxis under agarose: a new and simple method for measuring chemotaxis and spontaneous migration of human polymorphonuclear leukocytes and monocytes. F Immunol 1975; I15: 1650-1656.

20. Dixon WJ, Massey FJ. Introduction to statistical analysis. Kogakusha, Tokyo: McGraw-Hill, 1969: I 50-192.

2I. Dixon WJ, Massey FJ. Introduction to statistical analysis. Kogakusha, Tokyo: McGraw-Hill, I969: 334-345.

22. Bagdade JD, Root RK, Bulger RJ. Impaired leukocyte function in patients with poorly controlled diabetes. Diabetes $1974 ; 23: 9-15$.

23. Repine JE, Clawson CC, Goetz FC. Bactericidal function of neutrophils from patients with acute bacterial infections and from diabetics. $\mathcal{F}$ Infect Dis 1980 ; 142 : 869-875.

24. Mowat AG, Baum J. Chemotaxis of polymorphonuclear leukocytes from patients with diabetes mellitus. $N$ Engl 7 Med I97 I ; 284 : 62 I-627.

25. Aisen P. Some physicochemical aspects of iron metabolism. In: Iron Metabolism, Ciba Foundation Symposium 51. Elsevier/Excerpta Medica/North-Holland and Elsevier/ North-Holland Inc, 1977: I-I7.

26. Bullen JJ, Rogers HJ, Griffith E. Role of iron in bacterial infection. Curr Top Microbiol Immunol $1978 ; 80$ : I-35.

27. Schultz J, Rosenthal S. Iron(II) inactivation of myeloperoxidase. $\mathcal{F}$ Biol Chem 1959; 234: 2486-2490.

28. Walling C. Fenton's reagent revisited. Acc Clin Res $1975 ; 8: 125^{-1} 31$.

29. McCord JM, Day ED Jr. Superoxide-dependent production of hydroxyl radical catalyzed by iron EDTA complex. FEBS (Fed Eur Biochem Soc) Lett 1978; 86: 139-I 42.

30. Halliwell B. Biochemical mechanisms accounting for the toxic action of oxygen on living organisms: the key role of superoxide dismutase. Cell Biol Int Rep 1978; 2: 113-128.

31. Fridovich I. Superoxide dismutases. Ann Rev Biochem 1975; 44: I47-I 59.

32. Rosen $\mathrm{H}$, Klebanoff SJ. Bactericidal activity of a superoxide anion-generating system. A model for the polymorphonuclear leukocyte. 7 Exp Med 1979; 149: 27-39.

33. Salin ML, McCord JM. Free radicals and inflammation. Protection of phagocytosing leukocytes by superoxide dismutase. 7 Clin Invest 1975; 56: 1319-1323.

34. Ambruso DR, Johnston RB Jr. Lactoferrin enhances hydroxyl radical production by human neutrophils, neutrophil particulate fractions, and an enzymatic generating system. $\mathcal{F}$ Clin Invest 1981; 67: 352-360.

35. Ploem JE, de Wael J, Verloop MC, Punt K. Sideruria following a single dose of desferrioxamine-B as a diagnostic test in iron overload. Br f Haematol 1966; 12: 396-408. 